\title{
Research on the Construction of College English Follow-up Curriculum Based on Needs Assessment
}

\author{
Yanli Huang \\ School of Foreign Languages, City College of Dongguan University of Technology, Dongguan City, 523000, \\ Guangdong Province, P.R.China \\ *Corresponding author. Email: 594624259@qq.com
}

\begin{abstract}
Based on the theoretical framework of Needs Assessment, this article takes non-English major students from CCDUT as research sample and adopts questionnaire and interviews as research method to discuss the situation for opening the follow-up English curriculum in Chinese universities and colleges. Meanwhile, combined with the researching findings, suggestions are made in terms of course setting, textbook selection, course mode, evaluation and assessment, teacher training, etc., hence make a beneficial contribution to the improvement of education quality and realize the talent teaching in China.
\end{abstract}

Keywords: College English, The follow-up curriculum, Needs assessment.

\section{RESEARCH BACKGROUND}

The Chinese Ministry of Education newly issued the "Index to College English Teaching", pointing out that each college or university should formulate scientific, systematic and personalized college English syllabus to guide their College English teaching according to the actual situation, so as to improve the comprehensive cultural literacy of students to meet the needs of China's social development and international exchanges [1]. In fact, with the rapid growth of social demand for interdisciplinary talents who are proficient in both professional knowledge and English language, many colleges and universities in China have successively opened a series of College English follow-up curriculum to ensure the systematicity and continuity of English learning and provide more assistance to students with high demand in foreign languages (Generally, nonEnglish major students in China are just required to complete one or two years basic College English course in most Chinese universities).

However, through the study of the current status of College English teaching in China, the author found that the follow-up curriculum in most universities lacked the school-based and social-based considerations of the "localized" teaching model, which caused serious disconnect among the content of the curriculum, the students themselves and the actual social needs that has further resulted in the waste of educational resources.
As is known to us, the conditions, goals and background of each university are different, which requires that its English teaching should be based on the characteristics of the students of its own. Therefore, it is necessary to explore the construction of College English follow-up curriculum system based on both students' needs and social development and in line with local development to ensure students in different levels to obtain sufficient training. It is an urgent task of the reform of current College English teaching as well.

\section{RESEARCH SIGNIFICANCE}

College English follow-up curriculum is the extension of English courses at the basic stage. It usually refers to a series of senior and advanced English courses that meet the needs of students after their compulsory English courses are completed, including language skills courses, culture-related language courses, applied language courses and English courses for specific purposes [2][3]. So whether the follow-up curriculum can be carried out smoothly has a direct impact on the quality of English language talent training in China, and whether the courses can achieve the expected teaching goals depends on whether the curriculum is scientific and effective. Besides, curriculum setting mainly refers to the school's regulations on the types of courses, the sequence of courses, the allocation of course hours, the learning objectives and the teaching plans [4]. Needs assessment 
is the basis and prerequisite for curriculum design and implementation. It is also the basis for teachers to organize teaching, formulate syllabus, compile and use textbooks, explore effective teaching methods, evaluate teaching effects and organize after-class tutoring.

According to Hutchinson \& Waters, learner-centered needs can be divided into target needs and learning needs. The needs of learners are transformed into specific teaching activities through curriculum settings, and corresponding teaching links are designed on this basis [5]. Through Needs Assessment, on the one hand, learners' learning conditions, motivations, goals, attitudes and obstacles can be traced, and teaching plans can be determined to achieve teaching goals; on the other hand, we can understand the market's requirements for learners' various abilities by Needs Assessment, hence provide a reference for designing talent training programs. If the curriculum can be set up based on the vital interests of the students and has substantial value for their future development, the students will have clear learning goals and motivation, and the effectiveness of the curriculum will be increased accordingly.

Therefore, a comprehensive curriculum system should not only be limited to one aspect, but include the entire process of teaching and learning, that is, student level, curriculum design, teaching mode, and evaluation methods. Although many domestic scholars have conducted researches on English language teaching from the perspective of Needs Assessment, these studies are mostly concentrated on those universities where students have good English proficiency and foundation. The results of the researches are not fully applicable to all colleges or universities, especially schools where students have poor English foundation. At the same time, the research on the application of Needs Assessment in the construction of College English follow-up curriculum system is still relatively rare. In view of this, by means of questionnaire and interviews, this article adopts the Needs Assessment theory proposed by Hutchinson and Water as the theoretical framework to probe into the English learning needs of non-English majors in Chinese general colleges, aiming to provide ideas for the whole English curriculum system reforms.

\section{RESEARCH DESIGN}

\subsection{Research Sample and Object}

This article takes non-English major freshman of Grade 2019 of the City College of Dongguan University of Technology (CCDUT) as the research sample and object. CCDUT is an independent college approved by the Ministry of Education in China since June 2004. It is located in the southern part of Guangdong Province and has a wide range of students across the country, so students in CCDUT can represent the general situation of Chinese students to a certain extent. English courses in CCDUT are offered in the first and second semester of the freshman's year. Only a few follow-up English courses are available for some non-English majors in CCDUT.

\subsection{Research Methods and Questions}

The research is conducted in a combination of questionnaire and interview. The questionnaire is based on the Needs Assessment, including three sections in general: first, students' background information (including major, gender, years of English learning, English level and future career goals); second, students' overall evaluation of the current College English teaching system; third, students' needs for opening subsequent English (follow-up) courses (including teaching mode, course content, course objectives, opening time, assessment methods, textbooks, teaching methods, teacher qualifications, etc.). Students are required to choose the corresponding choice according to their actual situation. In addition, in order to make the sample more valid, on the basis of statistical questionnaire data, the author randomly selected some students to conduct in-depth interviews to get into their feedback on the follow-up English courses setting, so as to clarify the current problems and put forward some practical suggestions.

\subsection{Data Collection and Process}

The questionnaires were distributed both online and off-line in March, 2020. A total of 1560 questionnaires were distributed and 1060 valid questionnaires were collected, covering 567 students from Liberal Arts related majors, 221 students from Science related majors, 164 from engineering related students, and 108 Arts related students. Students surveyed come from 9 different departments and 35 different majors. The interviews were conducted one week after the questionnaire. The data collected are carried out through SPSS tools. Then combined with the data and information from questionnaires and interviews, the author aims to analyze the current status of College English teaching system and students' needs for the follow-up English curriculum.

\section{RESEARCH FINDINGS AND DISCUSSION}

\subsection{Analysis of Students' Background Information}

According to the Needs Assessment theory by Hutchinson \& Waters, language learners' learning expectations and goals has connection with learners' personal information. Learner's major, length of study, basic language level, future career goals, etc. all directly 
affect their motivation and needs for the choice of follow-up courses. Therefore, the author has designed corresponding questions in the first part of the questionnaire, aiming to make clear the general situation of English learning of non-English major students inordinary Chinese Universities and to discuss the necessity of construction of the follow-up English curriculum.

The research result shows that $76.42 \%$ of students have studied English for more than 9 years, and nearly $20 \%$ of them have studied for more than 13 years. This shows that the current basic English education of Chinese college students is much earlier than that in the past, which is in line with China's educational development history. Since the "Compulsory Education English Curriculum Standards" was issued in 2001, the starting year for English learning has been advanced from the first grade of junior high school to the third grade of elementary school, which means that most students have studied English for more than 10 years. However, currently, most of students' English proficiency is still at the stage of "dumb English" and "test-oriented English", and the ability of communication has still not been significantly improved The survey also tells that the current English level of Chinese students is relatively low. More than $90 \%$ of students have not passed any English language proficiency test, their basic English level is weak, and up to $80 \%$ of students are not satisfied with their own level of English proficiency. When it comes to the section "The future career goals", it shows that occupations that require relatively high English proficiency such as jobs in foreignfunded enterprise/joint venture, education industry and international finance industry are the most desirable career choices for students after graduation, accounting for one-third of the total.

As the society puts forward higher requirements on the English ability for college students, students from ordinary universities have shown stronger desire for English proficiency when compared to the past, and a basic College English course has been unable to meet the needs of social development for talents training. Under this trend, many well-known colleges and universities have set up corresponding follow-up advanced English courses to make up for the insufficient curriculum system. However, some localized colleges, like CCDUT, are restricted by factors like conditions, policies and faculty, the construction of follow-up English courses is relatively lagging behind. English Follow-up curriculum is part of the comprehensive system of College English reform, and it plays a key role in cultivating talents' comprehensive ability, therefore colleges and universities should open sufficient English courses according to the needs of students, hence help students gain more ability for their future career.

\subsection{Analysis of Students' Overall Evaluation on Current College English Teaching System}

In order to find out the current status of College English teaching and evaluate the effectiveness of basic English teaching in China, the author put forward some questions in the second section of the questionnaire, including "your overall evaluation on current College English teaching" , "your overall evaluation on current College English textbooks", "The English language skills you think you lack most", "Do you think it is necessary to open College English follow-up courses" and other related questions. Accordingly, students are required to make corresponding choices. Then the data result shows that students have a positive attitude towards the current College English teaching in general. $22.92 \%$ students are "very satisfied" and $6.79 \%$ are "relatively satisfied", and nearly $70 \%$ of the students believe that the current College English courses can basically satisfy their needs, but satisfaction with the course textbooks and teaching materials is not much good. It is shown that more than half of the students said that the content of the textbooks is too old-fashioned and exam-oriented, which has low relevance to their majors and future career, hence it is not very practical and helpful for them to improve their English proficiency.

In the column "The English language skills you think you lack most", "speaking and listening" account for $43.21 \%$ and $28.4 \%$ respectively, which are the two skills that students most urgently want to improve. At the same time, over $90 \%$ of students indicated that it is very necessary and relatively necessary to open followup advanced English courses. Furthermore, the author selected some students to conduct face-to-face interviews, trying to get into their opinions on the current problems in English teaching. Many students pointed out that the current teaching system is still carried out in an exam-oriented mode. Most English classes are still based on a single teacher-centered teaching mode. Vocabulary and text analysis are focused on, which affects students' interest in English learning, and makes their practical skills not effectively exercised and causes some students to be reluctant to indepth study after finishing exam tasks. This is also one of the main drawbacks of foreign language teaching for years in China. So it is obvious that the construction of College English follow-up curriculum can help get rid of the shortcomings of the basic courses to a large extent, hence provide students with more room for making progress and help reform the construction of the whole English curriculum system. 
Table1. Students' main purpose/motivation for choosing the follow-up English courses

\begin{tabular}{|c|c|c|c|c|c|}
\hline $\begin{array}{l}\text { Purpose/ } \\
\text { Motivation }\end{array}$ & $\begin{array}{l}\text { Enhance the } \\
\text { competitiveness of } \\
\text { future employment }\end{array}$ & $\begin{array}{c}\text { Pass English } \\
\text { qualification } \\
\text { examinations such as } \\
\text { CET-4 and CET-6 }\end{array}$ & $\begin{array}{l}\text { Improve } \\
\text { comprehen- } \\
\text { sive ability }\end{array}$ & $\begin{array}{l}\text { Prepare for } \\
\text { postgraduate } \\
\text { entrance } \\
\text { examination or } \\
\text { study abroad }\end{array}$ & $\begin{array}{l}\text { Understand } \\
\text { western } \\
\text { culture }\end{array}$ \\
\hline $\begin{array}{c}\text { Percentage } \\
(\%)\end{array}$ & 77.45 & 75.28 & 65 & 26.42 & 23.68 \\
\hline
\end{tabular}

Table 2. The types of college English follow-up courses that students expect

\begin{tabular}{ccccc}
\hline $\begin{array}{c}\text { Types of } \\
\text { courses }\end{array}$ & $\begin{array}{c}\text { courses related to } \\
\text { language skills }\end{array}$ & $\begin{array}{c}\text { courses related to } \\
\text { Language and culture }\end{array}$ & $\begin{array}{c}\text { courses related to } \\
\text { Language application }\end{array}$ & $\begin{array}{c}\text { courses with } \\
\text { special purpose }\end{array}$ \\
\hline number & 291 & 233 & 382 & 154 \\
$\begin{array}{c}\text { Percentage } \\
\%)\end{array}$ & 27.45 & 21.98 & 36.04 & 14.53 \\
\hline
\end{tabular}

Table 3.The content of College English follow-up course that students expect (multiple choices)

\begin{tabular}{cccccc}
\hline $\begin{array}{c}\text { Course } \\
\text { content }\end{array}$ & $\begin{array}{c}\text { English Speaking } \\
\text { and Debate }\end{array}$ & $\begin{array}{c}\text { Appreciation of } \\
\text { English Movies }\end{array}$ & $\begin{array}{c}\text { English for } \\
\text { Job-hunting }\end{array}$ & $\begin{array}{c}\text { English Viewing, } \\
\text { Listening and Speaking }\end{array}$ & $\begin{array}{c}\text { Tourism } \\
\text { English }\end{array}$ \\
\hline $\begin{array}{c}\text { Percentage } \\
\%\end{array}$ & 80.04 & 71.42 & 68.96 & 63.68 & 63.49 \\
\hline
\end{tabular}

\subsection{Analysis of Students' Motivation for the Follow-up English Curriculum}

Gardner and Lambert summarized the motivation of second language learning from the perspective of social psychology into two motivations: instrumental and integrative. Instrumental motivation means that learners' learning motivation is to achieve a specific purpose, while integrative motivation is the desire and interest of learning through the integration of second language learning [6]. Judging from the main purpose of choosing follow-up courses, we can see from Table 1 that $77.46 \%$ of students are to enhance their future employment competitiveness, followed by passing English qualification exams (75.28\%). It can be seen that instrumental motivation is the direct way for students to choose related follow-up courses, which is consistent with the students' desire to learn courses that are highly relevant to future employment as mentioned in the previous section. After all, in today's highly competitive job market, being able to master a foreign language will undoubtedly create more opportunities for themselves. In addition, Chinese society still highly recognizes foreign language qualification certificates, so students generally expect to increase the passing rate of such exams through the help of related follow-up courses. It shows that it is still necessary to provide with relevant exam-oriented follow-up English courses.
In terms of other purposes, integrative motivations such as improving the comprehensive ability (65\%) and understanding the western culture $(23.68 \%)$ are also important internal driving forces for students to study follow-up English courses. Some students also expressed their motivation of choosing follow-up courses are for hobbies, hoping to understand more about western culture, broaden their horizons, and perfect their own knowledge system. Of course, there are also a small number of students who say that the purpose of taking follow-up courses is just to fulfill the credit requirements. So the author believes that the current credit system in Chinese universities should be reformed, and prevent the follow-up courses from becoming "credit stations".

\subsection{Analysis of Students' Learning Needs for Follow-up English Curriculum}

The setting of college English follow-up curriculum should fully consider the actual needs of students and its practical value. For instance, CCDUT currently offers a few optional courses for non-English majors, such as "A Guide to English-Speaking Countries", "Tourism English, English Writing", "English Phonetics", etc., mainly based on basic skills courses and culture-related courses. However,there are fewer other follow-up courses to choose from, and applied courses that can 
improve students' competitiveness in job hunting are especially rare. To a certain extent, students' individual learning needs and overall development are ignored. So in order to figure out students' learning needs for follow-up courses, the author listed four types of courses to be opened in the third section of the questionnaire based on the actual situation of this school and referred to the advice of other universities, they are: (1) courses related to language skills; (2) courses related to Language and culture; (3) courses related to Language application; (4) courses with special purpose. Students are allowed to choose the follow-up courses they want to learn according to their own needs, so that we can truely understand the type of courses that students most need.

Students' learning needs for follow-up courses are reflected in the content and type of the courses. As shown in Table 2, students have the highest demand for language application courses. More than 36\% of students expect to improve their English practical ability through such courses; followed by language skills and language and culture courses, while courses with special purpose are relatively less demand. The author later learned through interviews that students generally expect to learn relatively practical courses, hoping such courses can be increased to help lay a solid foundation for their future career.

It can be seen from Table 3 that in the section of course content, the levels of demand in descending order are "English Speaking and Debate", "Appreciation of English Movies", "English for Job-hunting", "English Viewing,Listening and Speaking", and "Tourism English". "English Speaking and Debate" is the most popular among students. Up to $80 \%$ of students hope to take this course to improve their language skills and avoid "dumb English". Meanwhile, the proportion of students who choose "Appreciation of English Movies" and "English Viewing, Listening and Speaking" is also very high. Students said that through appreciating the materials provided by English films and native audiovisual sources, they can get in touch with the authentic pronunciation and intonation, which is beneficial to the improvement of listening and speaking abilities. At the same time, these courses can guide students to understand western culture and enhance their intercultural communication skills. Although CCDUT has opened relevant courses, the number of participants is limited and most of students are based on the purpose of fulfilling the required credit, which cannot meet the actual needs of students. In addition, some students have a strong favor to the exam-oriented courses such as CET-4, IELTS, TOEFL and other practical courses. It is expected that these courses can be added when provide with follow-up English courses. In the process of interview, students suggested that follow-up courses should be rich in types and be available to all students, so that they can choose what they really need.
Regarding the feedback on the course design, the author also asked the students' expectations for the teaching mode, opening time, edit and use of teaching materials, teacher allocation and testing and evaluation of the follow-up courses. Among them, $51.7 \%$ of students are more inclined to adopt the "online and offline" teaching mode. The combination of network learning and classroom teaching breaks the limitation of learning space, and can fully reflect the initiative and creativity of students as the main body of the learning process. Through the form of "human-computer interaction" and "MOOC teaching mode" to provide richer learning content, it can also provide teachers with rapid response to students' demand for different needs, hence improve teaching efficiency, so it has become the most popular teaching mode among students.

In terms of opening time, more than $60 \%$ of students hope that the follow-up courses can be opened for more than two semesters to ensure the learning effect. $32 \%$ of students are not satisfied with the current textbooks used in the courses. They think that the textbooks are too theoretical and boring, time-sensitive and lack interactive exercises. Most of the textbooks are not used at a high rate in fact. $50.47 \%$ of them expect the textbook can be compiled by native speakers, and the content of the textbooks can be designed with pictures and texts that are both interesting and keep up with the times.

In the survey concerning "Satisfaction with Teacher Deployment of Current College English Follow-up Courses", data shows that $52.8 \%$ of students have a positive attitude towards the teachers and are relatively satisfied with the teacher's teaching methods; $38.1 \%$ of the students hold a neutral position and believe that the teacher needs to adopt more flexible methods to mobilize the class atmosphere and increase teacherstudent interaction; however, $9.1 \%$ of students are not satisfied with the teacher's teaching methods, in their opinion, many teachers teach in "spoon feeding" style.

The author also interviewed and summarized the feedback from students, they said, "some teachers just 'read textbook' when in teaching, and the class atmosphere is dull, which resulting in students not being able to involve in class and the learning effect is not good". When asked "what is the most important factor for teachers who teach the follow-up courses", $61.98 \%$ of the students chose "humorous and vivid teaching style", followed by "rich teaching experience (24.25\%)", so the author suggests that universities and colleges should strengthen the training of teachers when setting up follow-up English courses. Teachers should pay more attention to the actual needs of students, improve teaching methods and efficiency. Moreover, with regard to "testing and evaluation methods", students believe that the assessment method needs to be reformed, which should be determined by the nature of the course, and 
they expect to adopt a diversified assessment method that focuses more on the learning process such as course essays or reports rather than a fixed closed-book exam format.

\section{CONCLUSION}

The research shows that in the new era, students' needs for College English follow-up courses show a trend of diversification and individuality. Universities and colleges should fully consider the needs of students from course settings, textbook selection, teaching models and methods to improve the current follow-up curriculum system. Furthermore, in order to increase the practical value of English courses,the follow-up curriculum should be reconstructed in terms of revolution of the ways of evaluation and assessment, teacher training, etc., so as to improve the design of teaching links and optimize teaching sources. With such effort, can the final goal of the follow-up English curriculum achieve the full integration of "cultural literacy $\rightarrow$ language skills $\rightarrow$ English application $\rightarrow$ special purpose", hence make a beneficial contribution to the improvement of education quality and realize the talent training in China.

\section{REFERENCES}

[1] Department of Higher Education, Ministry of Education of China. College English Course Teaching Requirements[Z]. Shanghai: Shanghai Foreign Language Education Press, 2007.

[2] Huang Bing. The Construction of College English Follow-up Courses in Minority Areas [J]. Sichuan: Journal of Southwest University for Nationalities, 2009(1): 264-267.

[3] Huang Yingqiu. Investigation and Thoughts on the Follow-up Course System of College English in Guangxi Colleges and Universities [J]. Yunan: Journal of Yunnan University of Finance and Economics, 2006(5):139-140.

[4] Hutchinson,T., \& Waters,A. English for Specific Purposes-A Learning-centered Approach[M]. Cambridge: Cambridge University Press, 1987.

[5] Ji Chengjun. Introduction to University Courses [M]. Shanghai: Shanghai Education Press, 2007:147.

[6] [Wu Yue. A Study on the Satisfaction of College English Follow-up Curriculum Based on the Analysis of Student Needs[R]. Nanjing: Nanjing University of Aeronautics and Astronautics, 2017:25. 